\title{
MERUMUSKAN PEMIKIRAN EKONOM MUSLIM TENTANG RASIONALITAS DALAM PERILAKU KONSUMEN
}

\author{
Lia Istifhama ${ }^{1}$ \\ e-mail : liaistifhamah@gmail.com \\ STAI TARUNA SURABAYA
}

\begin{abstract}
Abstrak : rationality is the characteristic of any action, belief, or desire, that makes their choice optimal under a set of constraints. ${ }^{[1]}$ It is a normative concept of reasoning in the sense that rational people should derive conclusions in a consistent way given the information at disposal. It refers to the conformity of one's beliefs with one's reasons to believe, or with one's actions with one's reasons for action. However, the term "rationality" tends to be used differently in different disciplines, including specialized discussions of economics, sociology, psychology, evolutionary biology and political science. A rational decision is one that is not just reasoned, but is also optimal for achieving a goal or solving a problem.
\end{abstract}

Kata Kunci : rasionalitas, perilaku konsumen, pengambilan keputusan.

\section{A. PENDAHULUAN}

Perilaku konsumen merupakan respon psikologis yang kompleks yang muncul dalam bentuk perilaku-tindakan yang khas secara perseorangan yang langsung terlibat dalam usaha memperoleh, menggunakan produk, dan menentukan proses pengambilan keputusan dalam melakukan pembelian produk. ${ }^{2}$ Dalam berperilaku, decision making yang dibuat konsumen tentunya berdasarkan pertimbangan rasionalitas.

Suatu keputusan yang dibuat adalah "rasional". Biasanya, kita mengadopsi pandangan lebih luas dan menilai rasionalitas tidak hanya dalam istilah "best interests" (kepentingan/ keperluan terbaik) seseorang yang dipertimbangkan dalam pengambilan keputusan, namun suatu best interest yang didefinisikan sebagai kepentingan bersama. Keputusan yang baik atas beragam pilihan ialah dipilih sesuai tujuan yang ingin dicapai oleh pengambil keputusan yang sekaligus pemilik tujuan (personal). ${ }^{3}$ Oleh sebab itu, rasionalitas disebut juga quality of choice, suatu kualitas atas pilihan yang ada.

\footnotetext{
${ }^{1}$ Dosen tetap STAI Taruna Surabaya.

${ }^{2}$ Ali Hasan, Marketing Bank Syariah (Bogor: PT. Ghalia Indonesia, 2010), 50.

${ }^{3}$ Reid Hastie and Robyn M. Dawes, Rational, Choice, in an Uncertain World (London: Sage Publications, 2001), 17.
} 
Terkait dengan pilihan, suatu pilihan yang dikatakan rasional dapat didefinisikan atas 4 kriteria:

1. Berdasarkan apa yang dimiliki oleh pembuat keputusan saat ini. Kepemilikan tidak hanya termasuk uang, tapi juga psikologi, hubungan sosial, dan perasaan.

2. Berdasarkan resiko yang mungkin terjadi atas pilihan.

3. Ketika resiko tidak pasti terjadi, maka dapat dievaluasi teori probabilitas atau kemungkinan-kemungkinan yang ada.

4. Pilihan bersifat adaptif, dimana dibatasi dengan kemungkinan resiko yang buruk dan kemungkinan nilai-nilai kepuasan.

Keempat kriteria rasionalitas tersebut memiliki dasar filosofi. Jika ada yang dilanggar, maka pembuat keputusan dapat mencapai kesimpulan yang kontradiktif (bertentangan) dengan apa yang dipilih. Namun kerasionalan dapat tidak sesuai dengan realita yang diharapkan. ${ }^{4}$

Ekonomi Konvensional menjelaskan bahwa ada beberapa kebiasaan dalam prosedur pengambilan keputusan yang tidak berhubungan langsung dengan rasionalitas, yaitu:

a.Kebiasaan atau pilihan yang pernah dipilih sebelumnya

b. Kenyamanan, atau pilihan yang dapat membanggakan diri.

c.Prinsip keagamaan dan budaya. ${ }^{5}$

Namun Islam memandang berbeda, dimana prinsip keagamaan memiliki urgensi untuk dilibatkan dalam proses decision making.

\section{B. RASIONALITAS DALAM EKONOMI ISLAM}

Pemikiran ekonomi Islam memandang rasionalitas bermakna bahwa konsumen merupakan sosok cerdas, sehingga memiliki beberapa sikap, seperti: sikap netral, menentukan sesuatu dengan dasar alasan yang dapat diterima secara logika atau dapat dijelaskan dan bertujuan. ${ }^{6}$ Lebih lanjut, Syed Omar Syed Agil mengklasifikasikan pengeluaran dalam perilaku ekonomi sesuai pandangan rasionalitas Islam:

a.Pengeluaran untuk meraih kesuksesan dalam hidup, yang meliputi: konsumsi dan tabungan/ investasi,

\footnotetext{
${ }^{4}$ Ibid., 18.

${ }^{5}$ lbid. 18.

6 Syed Omar Syed Agil, Economics Rationality, dalam Sayyid Tahir (ed.), dkk. Readings in Microeconomics: an Islamic Perspective. Chapter Fourteen, Ibn Taimiyyah's Concept of Market Mechanism, 'Abdul 'Azim Islahi (Malaysia: Longman Malaysia, 1992), 31.
} 
b. Pengeluaran sebagai bekal di akhirat. ${ }^{7}$

Adapun Kurshid Ahmad menjelaskan bahwa ada tiga hal dalam teori konsumen yang terkait dengan motif rasional, yaitu: a) Seorang konsumen dapat membuat peringkat, sesuai dengan pilihannya, komoditas mana yang harus ia pilih; b) Pilihan seorang konsumen adalah konsisten dengan selera atau rasa yang paling memenuhi kelengkapan yang diinginkan; dan c) Hubungan antara harga barang dan penghasilan menyediakan pilihan yang meyakinkan yang membuat ia menentukan pilihan ${ }^{8}$.

Konsumen tentunya berperilaku untuk mencapai tujuannya, yang dalam islam, dikenal dengan istilah fala $>h\{$. Nejatullah Siddiqi menjelaskan dominasi atas perilaku konsumen mencapai fala $>\mathrm{h}\{$ menurut Islam:

a.Keimanan kepada hari akhir dan hari penghitungan amal

b. Konsep berhasil dalam Islam. Berhasil atau sukses dalam arti tersebut ditujukan kepada Allah SWT, bukan semata mencari kemakuran.

c.Konsep kekayaan. Harta dalam islam diyakini sebagai pemberian dari Allah SWT. Harta dapat menjadi jalan ibadah, juga justru dapat menjadi jalan bermunkar sesuai perbuatan manusia. Oleh sebab itu, manusia yang memiliki kekayaan lebih harus menyadari bahwa itu hanya titipan dan harus memenuhi kewajibannya atas orang miskin (seperti zakat). ${ }^{9}$

Ketiga hal tersebut menunjukkan bahwa Nejatullah Siddiqi merumuskan salah satu tujuan rasionalitas konsumen, yaitu bertujuan normatif. Dalam hal ini, rasionalitas dalam berperilaku ekonomi memiliki dimensi transendental, yaitu bertujuan menjalankan kewajiban kepada Allah SWT ataupn tujuan akhirat.

Hal ini yang kemudian menjadi pembeda utama antara rasionalitas barat dan islam, dimana islam mengedepankan social interest, yang didalamnya termasuk distribusi pendapatan.

Dalam hal ini, Ekonomi Barat berasumsi bahwa perilaku individu adalah rasional. Perilaku rasional secara otomatis akan menjadi perilaku yang disadari atas tujuan tertentu, baik ekonomi atau non ekonomi. Sebagai contoh, pemikiran pengikut Darwin menjelaskan bahwa rasionalitas disamakan dengan pelayanan atas kepentingan pribadi (self interest). They interpret the drive of self interest in man as the moral equivalent of the force of gravity in nature. Kemudian, mereka menginterpretasikan

\footnotetext{
${ }^{7}$ Ibid., 42.

${ }^{8}$ Ausaf Ahmad and Kazim Raza Awan (ed.), Lectures on Islamic Economics (Jeddah: Islamic Research and Training Institute IDB, 1987), 170.

${ }^{9}$ Khurshid Ahmad, (ed.), Studies in Islamic Economics (Jeddah: King Abdul Aziz University, 1980), 24.
} 
kepentingan pribadi manusia sebagai moral yang sepadan dengan kekuatan untuk menghadapi gravitasi pada kehidupan alam semesta. ${ }^{10}$

Selain itu, Edgeworth pun mengekpresikan pemikirannya dalam pernyataan: the first principle of economics is that every agent is activated only by self interest (prinsip utama ahli ekonomi bahwa setiap pelaku ekonomi berperilaku berdasarkan kepentingan pribadi). ${ }^{11}$ Terkait dengan kerangka ini, masyarakat mengkonseptualisasikan kumpulan individu semata melalui pertalian self interest atau kepentingan pribadi tersebut. Hal ini, namun, memungkinkan penyajian kepentingan pribadi dalam cara yang berbeda, seperti halnya dalam hal ilmu ekonomi ataupun non ekonomi. Tapi, ini menjaga dengan orientasi materialistik, maka rasionalitas pun disamakan dengan hal yang berkaitan dengan ekonomi dan uang (pecuniary).

Hal ini menunjukkan bahwa ilmu ekonomi barat membangun konsep bahwa pelaku ekonomi adalah one and only one social responsibility is to increase his profit (individu yang bertanggungjawab meningkatkan keuntungannya). ${ }^{12}$ Otomatis, ilmu memperhatikan perilaku ekonomi rasional manusia (behaviour of rational economic man) hanya dimotivasi atau didorong melalui kepentingan pribadi melalui pemaksimalan kesejahteraan dan konsumsinya dalam berbagai cara yang ia bisa. Semua keinginan manusia menyatu bersama-sama, seperti cooperation (kerjasama), compassion (perasaan kasihan/ terharu dengan orang lain), brotherhood (persaudaraan), dan altruism (mementingkan kepentingan orang lain), dimana manusia berjuang untuk kesejahteraan yang lain meskipun akan menyakiti atau merusak kepentingan pribadinya, akan ditolak (oleh konvensional). ${ }^{13}$

Kembali dalam pilihan rasional menurut ekonomi Islam, dijelaskan oleh Ausaf Ahmad bahwa ada dua aspek pilihan dalam perspektif Islam: pertama, menyimpan sesuatu sebagai konsumsi masa depan adalah hal yang sangat diizinkan. Apa yang dipersiapkan untuk masa depan, bukan semata harta, karena setelah orang meninggal, harta bukan berarti apa-apa. Kedua, harapan akan tingkat pengembalian tabungan (dengan bagi hasil atau balasan) merupakan

\footnotetext{
${ }^{10}$ Milton L. Myers, The Soul of Modern Economic Man: Ideas of Self Interest, Thomas Hobbes to Adam Smith (Chicago: University of Chicago Press, 1983), 4.

${ }^{11}$ F.Y. Edgeworth, Mathematical Psychics: An Essay on the Application of Mathematics to the Moral Science (London: Kegan Paul, 1881), 16.

12 Milton Friedman, Capitalism and Freedom (Chicago: The University of Chicago Press, 1972), 133.

${ }^{13}$ M. Umer Chapra, The Future of Economics: An Islamic Perspective (Leicester: The Islamic Foundation, 2000), 22.
} 
motivasi menabung yang lebih efektif dalam Islam daripada tingkat bunga. Seperti halnya zakat yang mendapat balasan tersendiri dari Allah. ${ }^{14}$

Ia juga menjelaskan beberapa pilihan konsumen untuk mengalokasi kebutuhan sesuai sumber daya (Consumer Choice for Allocation of Resources)

a. Pilihan utama: wordly needs (kebutuhan utama yang tidak ada alasan untuk tidak dipenuhi), cause of Allah (ibadah).

b. Pilihan kedua: present consumption (kebutuhan masa sekarang), future consumption (kebutuhan masa datang)

c. Pilihan ketiga: essentials (kebutuhan penting), amelioratories (kebutuhan untuk perbaikan/ kenyamanan)

d. Pilihan keempat: pilihan diantara substitusi atau beragam alternatif. ${ }^{15}$

Pilihan-pilihan konsumen yang ditentukan oleh Ausaf Ahmad tersebut tentunya merupakan pilihan yang wajar sesuai tujuan/ maslah\{ah yang diinginkan (present aim rationality).

Maslah\{ah disini ialah yang mengandung kebaikan bagi pribadi maupun orang lain. Islam memandang wajar ketika seseorang mencapai maslah\{ah dalam dua hal: $\operatorname{maslah}\{$ ah yang selalu lebih besar atau disukai, dan maslah $\{$ ah yang diupayakan terus meningkat sepanjang waktu atau yang disebut konsep quasi concavity yang menunjukkan pola non-decreasing. Hal ini tentunya ntuk mencapai falah\{ yang lebih baik (h\{ayat $\mathrm{t}\{$ ayyibah).

Kebolehan atas sesuatu yang wajar juga telah dijelaskan oleh Yousuf Kamal Muhammad, bahwa konsep asceticism (pertapaan seperti kaum sufi) dalam Islam bukan untuk melarang apa yang sebenarnya diizinkan untuk mencapai kesejahteraan, tapi untuk mempercayai apa yang menjadi kehendak atau dikendalikan Allah dan yang dapat dikendalikan manusia, dengan tujuan agar manusia tidak menyesal. ${ }^{16}$ Hal ini pun tertuang dalam Al-Qur'a>n, yang diantaranya sebagai berikut:

Al Ma'idah ayat 87:

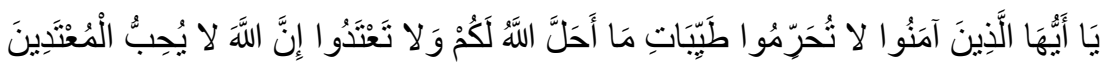

\footnotetext{
${ }^{14}$ Ahmad, Islamic Economics, 172-172.

15 Ibid., 178.

16 Yousuf Kamal Muhammad, The Principles of The Islamic Economic System (Cairo: Islamic Inc. Publishing \& Distribution, 1636 M), 155.
} 
Hai orang-orang yang beriman, janganlah kamu haramkan apa-apa yang baik yang telah Allah halalkan bagi kamu, dan janganlah kamu melampaui batas. Sesungguhnya Allah tidak menyukai orang-orang yang melampaui batas.

Al Ma'idah ayat 88:

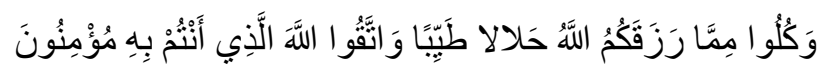

Dan makanlah makanan yang halal lagi baik dari apa yang Allah telah rezekikan kepadamu, dan bertakwalah kepada Allah yang kamu beriman kepada-Nya.

Al Shat $\{$ ibi berkata bahwa apa yang menjadi firman Allah SWT tersebut menunjukkan bahwa kesenangan bagi manusia sebenarnya sah menurut hukum selama tidak bersifat haram dan berbahaya bagi manusia. ${ }^{17}$ Lebih lanjut, ia menjelaskan bahwa Islam telah memaparkan bahwa fulfilling needs (memenuhi kebutuhan) berbeda dengan satisfying wants (memuaskan keinginan). Dalam hal ini, ada perbedaan antara necessities (kebutuhan yang dirasa penting), needs (kebutuhan yang memang diperlukan), dan peningkatan. Necessities bertujuan melayani kepentingan keagamaan dan keduniaan. Jika kewajiban ini dilanggar, maka dapat merusak kehidupan dunia dan kegagalan dalam keselamatan akhirat. Sedangkan tujuan dari needs adalah memperluas kemampuan sehingga mengeliminasi kesempitan/ kekurangan dalam membentuk kehidupan yang sejahtera. Oleh sebab itu, jika needs tidak terpenuhi, dapat membuat manusia hidup kekurangan. Tujuan dari peningkatan (kehidupan) adalah untuk memperbaiki kebiasaan dan menghindari penodaan dalam pemikiran manusia, termasuk didalamnya adalah kebaikan moral. Islam sendiri meyakini bahwa distribusi pendapatan bisa menciptakan equity kekayaan antara yang kaya dan miskin sehingga menghindari kemiskinan dan monopoli kekayaan. Dengan begitu, Islam telah menganjurkan keseimbangan kebutuhan dunia dan akhirat. ${ }^{18}$

Adapun menurut Siddiqi, konsumen akan berorientasi mencapai kenyamanan maksimal dalam berkonsumsi, dan hal itu diperbolehkan selama sesuai norma Islam. sedangkan Kahf menegaskan, bahwa dasar dari konsumsi, adalah ketepatan dalam hal maksimasi atas konteks perilaku konsumen dalam Islam, yaitu harus sesuai norma Islam. Dalam hal ini, konsumsi barang mewah, hal-hal spekulasi atau unsur perjudian,

\footnotetext{
17 Ibid., 156.

18 Ibid., 161.
} 
kesenangan (wanita), dan hal yang sia-sia adalah dilarang. ${ }^{19}$ Namun Islam juga menolak pola pengeluaran niggardliness ( $b u k h l$ ), yaitu kekikiran.

Dengan begitu, konsumsi merupakan pilihan yang tepat untuk menghindari kemubadziran sumber daya yang bisa dimanfaatkan. Namun pemanfaatan apa yang ada harus setimpal dengan pengorbanan untuk mendapatkannya, tidak boleh ada kesia-siaan ataupn sesuatu yang berlebihan. Namun pendayagunaan sumber daya alam harus dilakukan sesuai norma Islam dan bukan kemewahan. Baqir al $\mathrm{S}\{\mathrm{adr}$ mengusulkan bahwa sumber daya seharusnya tidak diperbolehkan untuk dialihkan dalam produksi barang mewah sampai produksi kebutuhan yang penting dijamin jumlahnya terus mencukupi. Dengan begitu, konsumen semestinya tidak masuk dalam pengeluaran barang mewah di luar pemenuhan kebutuhan penting. ${ }^{20}$

Al Furqa $>$ n ayat 67

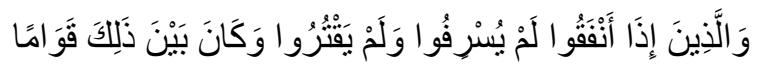

Dan orang-orang yang apabila membelanjakan (harta), mereka tidak berlebihlebihan, dan tidak (pula) kikir, dan adalah (pembelanjaan itu) di tengah-tengah antara yang demikian.

Salah satu ekonom Muslim, Afzalur Rahman, menyampaikan pandangannya: "Islam made it obligatory to maintain and develop human life in order that every member of the state should be able to obtain his basic necessities of life including food, clothing, and shelter, etc. ${ }^{21}$ Similarly, enjoyment of comfort is considered to be permissible in Islam provided it remains within limits and does not lead to excesses." 22 (Islam mewajibkan memelihara dan membangun kehidupan manusia sebagai tujuan setiap anggota masyarakat dalam negara yang seharusnya mampu memperoleh apa yang menjadi kebutuhan pokoknya, termasuk yaitu: makanan, pakaian, perlindungan diri, dsb. Dengan cara yang sama, manusia menikmati kenyamanan, yaitu memperhitungkan sekaligus mempertimbangan apa yang dibolehkan dalam Islam yang dalam batas yang wajar (sisanya bukan mubadzir) dan tidak berlebihan).

\footnotetext{
${ }^{19}$ M. Nejatullah Siddiqi, Muslim Economic Thinking (Jeddah: King Abdul Aziz University, 1981), 54-55. ${ }^{20}$ lbid., 17.

${ }^{21}$ Afzalur Rahman, Economic Doctrines of Islam, Vo. I \& II (Lahore: Islamic Publications Ltd., 1980), 22.

22 Ibid., 27.
} 
Juga diterangkan lagi oleh Afzalur Rahman terkait barang mewah: Has forbidden the use of luxuries as they encourage the growth of unproductive and immoral industries and spread mischievous and disruptive elements in the society which ultimately destroy the unity and integrity of the entire community. ${ }^{23}$ (Adalah dilarang atas penggunaan barang mewah yang hanya mendorong pertumbuhan barang tidak produktif (kurang berguna) dan industri non moral dan menyebarkan kerugian dan kekacauan elemen dalam masyarakat dimana akhirnya merusak kesatuan dan integritas dalam seluruh masyarakat).

Terkait pendayagunaan sumber daya alam sebagai barang mewah, menarik untuk disimak pernyataan Ausaf Ahmad terhadap permintaan barang mewah:

"Pertama, ini tidak seperti pengertian bahwa permintaan terhadap barang mewah tidak ada sama sekali dalam konteks Islam. Karena mungkin saja secara logika, permintaan barang mewah akan melemah dan berkurang pada masyarakat yang tingkat kesalehan dan kealimannya tinggi. Konsekuensinya, barang mewah pun tidak penting lagi. Kedua, kebutuhan barang mewah bisa jadi sebagai bahwa ada terminologi relatif yang menjadi permasalahan. Apa yang menjadi penting bagi seseorang, bisa jadi adalah hal pelengkap atau penambah kenyamanan, dan bisa jadi diartikan sebagai barang mewah bagi orang lain. Mewah tidaknya suatu barang dapat dipengaruhi oleh tingkat sosial, ekonomi, dan pertumbuhan teknologi dalam masyarakat. Ketiga, tidak bisa dikatakan bahwa Islam secara mutlak melarang barang mewah. Namun, Islam mengecilkan upaya seseorang mengkonsumsi barang mewah, terlebih dalam skala luar biasa dan berlebihan, karena penggunaan secara berlebihan akan merusak moral masyarakat." 24

Oleh sebab itu, rasionalitas konsumen juga berfungsi sebagai upaya memilih yang meminimumkan resiko (risk aversion). Dalam hal ini, ada dua resiko yang dimaksud, yaitu resiko yang bernilai (worthed risk) dimana memang ada nilai pengorbanan untuk mendapatkan sesuatu, dan resiko yang tidak bernilai dimana hasil yang didapatkan lebih kecil atau tidak sebanding dengan pengorbanan. Resiko yang kedua ini merupakan dampak dari perilaku hedonisme yang hanya mengandalkan kepuasan. Padahal dalam ekonomi Islam, untuk melengkapi kepuasan, dimana sebagai tujuan maksimal yang

${ }^{23}$ Ibid.

${ }^{24}$ Ahmad, Islamic Economics, 252. 
diinginkan, hal ini tidaklah berhubungan dengan kemampuan mental dan tafakur manusia.

Al-Baidawy (wafat $791 \mathrm{H}$ ), berkata bahwa hampir semua kewajiban atas alam (merawat dan memelihara alam) diselesaikan dengan rasa malas/ enggan, meskipun mereka adalah bentuk hak (yang harus dipenuhi) dan menyebabkan keberhasilan (jika alam dirawat dengan baik). Sebaliknya, apa yang dilarang justru merupakan keinginan dan dihargai oleh personal (untuk dipenuhi) meskipun mencakup hal-hal yang menimbulkan kerusakan". ${ }^{25}$

Begitupun Ibnu Taimiyah (w. 738 H) menyatakan: "Kepuasan absolut (mutlak) sebenarnya merupakan sesuatu (pemanfaatan kegunaan barang) yang jumlahnya berlebihan. Jika ini untuk mencegah sesuatu yang berlebihan atau yang dapat menimbulkan kerusakan, ini merupakan tidak benar untuk dipertimbangkan. Juga, apa yang terlihat berguna meskipun ternyata tidak, atau yang darinya menjadi sumber atas kepuasan yang kemudian merusak, tidak lagi menjadi kegunaan sepenuhnya. Oleh sebab itu, apa yang dilarang oleh Allah SWT dan para RasulNya adalah hal-hal yang memang merugikan bagi manusia, dimana tidak memiliki kegunaan dan hanya berlebihan". ${ }^{26}$

Lebih lanjut, imam Ghazali (w. 505 H) mengilustrasikan sebagai berikut: "Semua hal dipisahkan sesuai kepentingannya dalam dunia dan akhirat. Ilmu pengetahuan dan perilaku, dipisahkan apa yang berbahaya di dunia yang harus dihindari atau dilarang. Juga, apa yang penting sekarang dan sesuatu yang menimbulkan bahaya di kemudian hari, seperti mencari kepuasan atau kesenangan melalui naluri atau hasrat pengeluaran, dan itu menjadi kondisi yang berbahaya dan keuntungan kemudian, seperti dengan cara memendam keinginan dan menentang hasrat/ nafsu.

Dari ketiga pernyataan tokoh ekonom Muslim, kepuasan yang berada di atas kualitas kebutuhan dapat menjadi hal yang tidak tepat, berbahaya, dan menimbulkan penderitaan. Sebaliknya, akan menjadi penghormatan yang riil ketika kepuasan dan keuntungan yang didapat ialah berasal dari ilmu pengetahuan ataupun perilaku ekonomi yang cerdas, yang memiliki rasionalitas sesuai ekonomi Islam.

\footnotetext{
${ }^{25}$ Muhammad, Islamic Economic System, 152.

${ }^{26}$ Ibid., 152.
} 
Yousuf Kamal Muhammad menjelaskan bahwa manusia memiliki tiga macam kebutuhan yang menghasilkan kepuasan:

1. Kebutuhan intelektal: ini merupakan kebutuhan yang dicapai dari ilmu pengetahuan dan kebijaksanaan (hikmah/logika). Oleh karena itu, ini tidak dinikmati melalui indera penglihatan, penciuman, perasa, makanan atau seksual, tapi lebih kepada hati, yang dipresentasikan melalui pikiran, sebagai satu-satunya organ yang merasakan kesenangan. Kebutuhan ini dibatasi dengan hasil karya manusia yang akhirnya dinikmati dan hampir sepenuhnya sebagai kebutuhan yang memenuhi kegunaan/manfaat bagi manusia di bumi.

2. Seperti umumnya pada binatang, manusia mendapatkan kepuasan dari kepemilikan kekuatan, kedaulatan, pemberian, sebagai contoh singa, harimau, dan sebagainya.

3. Seperti halnya semua makhluk hidup, manusia mencapai kepuasan dari makanan dan seksual. Ini merupakan bentuk kepuasan yang paling rendah. ${ }^{27}$

Dari kesemuanya, manusia yang termasuk dalam kategori ketiga, adalah mereka yang terobsesi kekuatan dan kelak merugi. Sedangkan yang termasuk kategori pertama, manusia akan menikmati pengetahuan dan kebijaksanaan/ hikmah, yang kemudian mencapai level pengetahuan keimanan kepada Allah SWT. Ini merupakan peringkat bagi orang suci.

Meski begitu, Allah SWT mengizinkan manusia mencari perhiasan dunia/ kekayaan sesuai kebutuhan. Hal ini yang termaktub dalam surat Al-A'raf ayat 32:

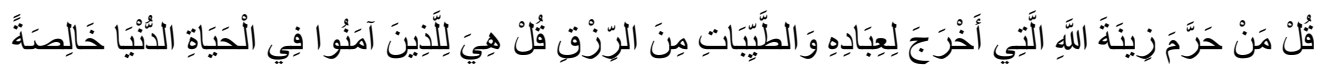

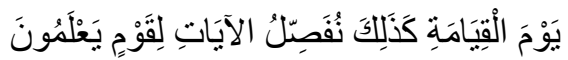

Katakanlah: "Siapakah yang mengharamkan perhiasan dari Allah yang telah dikeluarkan-Nya untuk hamba-hamba-Nya dan (siapa pulakah yang mengharamkan) rezeki yang baik?" Katakanlah: "Semuanya itu (disediakan) bagi orang-orang yang beriman dalam kehidupan dunia, khusus (untuk mereka saja) di hari kiamat. Demikianlah Kami menjelaskan ayat-ayat itu bagi orang-orang yang mengetahui.

Dengan begitu, Yousuf Kamal Muhammad menjelaskan bahwa konsep asceticism (pertapaan seperti kaum sufi) dalam Islam bukan untuk melarang apa yang sebenarnya diizinkan untuk mencapai kesejahteraan, tapi untuk mempercayai apa yang menjadi kehendak atau dikendalikan Allah dan yang dapat dikendalikan manusia, dengan tujuan agar manusia tidak menyesal. ${ }^{28}$

\footnotetext{
27 Ibid., 153.

28 Ibid., 155.
} 
Al Ma'idah ayat 87:

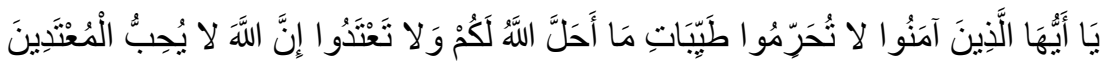

Hai orang-orang yang beriman, janganlah kamu haramkan apa-apa yang baik yang telah Allah halalkan bagi kamu, dan janganlah kamu melampaui batas. Sesungguhnya Allah tidak menyukai orang-orang yang melampaui batas.

Al Ma'idah ayat 88:

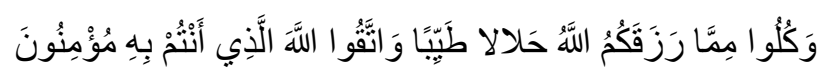

Dan makanlah makanan yang halal lagi baik dari apa yang Allah telah rezekikan kepadamu, dan bertakwalah kepada Allah yang kamu beriman kepada-Nya.

Al Shatibi berkata bahwa apa yang menjadi firman Allah SWT tersebut menunjukkan bahwa kesenangan bagi manusia sebenarnya sah menurut hukum selama tidak yang telah jelas bersifat haram dan berbahaya bagi manusia. ${ }^{29}$

Adapun sifat rasionalitas lainnya menurut Islam adalah sebagai upaya memilih untuk menghindari ketidakpastian (uncertainty). Dalam hal ini, konsumen harus melengkapi informasi dan pengetahuan agar mendapatkan keakuratan.

\section{PENUTUP}

Berdasarkan kajian pemikiran ekonomi islam terkait rasionalitas, penulis berusaha merumuskan rasionalitas ekonomi Islam dalam 6 hal: rasionalitas bertujuan normatif, pilihan yang wajar sesuai tujuan/ maslah\{ah yang diinginkan (present aim rationality), pilihan yang tepat untuk menghindari kemubadziran sumber daya yang bisa dimanfaatkan, upaya memilih yang meminimumkan resiko (risk aversion), social interest, yang didalamnya termasuk distribusi pendapatan, dan upaya memilih untuk menghindari ketidakpastian (uncertainty).

${ }^{29}$ Ibid., 156. 


\section{DAFTAR PUSTAKA}

Ahmad, Ausaf and Kazim Raza Awan (ed.). Lectures on Islamic Economics. Jeddah: Islamic Research and Training Institute IDB, 1987.

Ahmad, Khurshid (ed.). Studies in Islamic Economics. Jeddah: King Abdul Aziz University, 1980.

Chapra, M. Umer. The Future of Economics: An Islamic Perspective. Leicester: The Islamic Foundation, 2000.

Edgeworth, F.Y., Mathematical Psychics: An Essay on the Application of Mathematics to the Moral Science. London: Kegan Paul, 1881.

Friedman, Milton. Capitalism and Freedom. Chicago: The University of Chicago Press, 1972.

Hasan, Ali. Marketing Bank Syariah. Bogor: PT. Ghalia Indonesia, 2010.

Hastie, Reid, dan Robyn M. Dawes. Rational, Choice, in an Uncertain World. London: Sage Publications, 2001.

Muhammad, Yousuf Kamal. The Principles of the Islamic Economic System. Cairo: Islamic Inc. Publishing \& Distribution, $1636 \mathrm{M}$.

Myers, Milton L. The Soul of Modern Economic Man: Ideas of Self Interest, Thomas Hobbes to Adam Smith. Chicago: University of Chicago Press, 1983.

Rahman, Afzalur. Economic Doctrines of Islam, Vo. I \& II Lahore: Islamic Publications Ltd., 1980.

Siddiqi, M. Nejatullah. Muslim Economic Thinking. Jeddah: King Abdul Aziz University, 1981.

Tahir, Sayyid (ed.), dkk. Readings in Microeconomics: an Islamic Perspective. Malaysia: Longman Malaysia, 1992. 